\title{
Ergenlerde Ebeveyn Tutumları ve Duygusal Zekâ İlişkisi: Benlik Saygısının Aracı Rolü
}

\author{
Doç. Dr. Üyesi Ferzan CURUN* \\ Maltepe Üniversitesi, Psikoloji Bölümü, Marmara Eğitim Köyü, Maltepe / İstanbul / Türkiye, \\ fcurun@yahoo.com, ORCID: 0000-0002-9221-2822
}

\section{Uzm. Duygu ORÇUN-YÜCEL}

duygu.orcun@hotmail.com, ORCID: 0000-0002-4372-8152

\section{$\ddot{\mathbf{O} z}$}

Bu çalışmada ebeveyn tutumları, benlik saygısı ve duygusal zekâ arasındaki ilişki 233 ergenden oluşan bir örneklemle araştırılmıştır (125 kız ve 108 erkek). Çalışmanın değişkenleri Ana-Baba Tutum Ölçeği, Rosenberg Benlik Saygısı Ölçeği, Bar-On Duygusal Zekâ Ölçeği ve Demografik Bilgi Formu ile ölçülmüştür. Verilerin analizi için, öncelikle araştırmanın değişkenleri arasındaki ilişkiler Pearson Momentler Çarpım Korelasyonu ile incelenmiş, daha sonra, ebeveyn tutumlarının duygusal zekâ üzerinde benlik saygısının aracı etkisi araştırılırken öncelikle tekil ilişkilere bakılmış, sonrasında ise aracılık modellenmiştir. Beklentilerle tutarlı olarak çalışmanın değişkenleri arasında anlamlı ilişkiler bulunmuştur. Ayrıca benlik saygısı hem demokratik hem de otoriter ebeveyn tutumlarının duygusal zekâ ile olan ilişkisine kısmî aracılık etmiş ancak koruyucu istekçi ebeveyn tutumuna ilişkin anlamlı sonuçlar bulunmamıştır. Sonuçlar ilgili alanyazın temelinde tartışılmıştır.

* Sorumlu Yazar. Tel: +90 5323600430

(C) 2018 Kalem Eğitim ve Sağlık Hizmetleri Vakfı. Bütün Hakları Saklıdır. 
Anahtar Kelimeler: Ebeveyn tutumları; Ebeveyn stilleri; Benlik saygısı; Duygusal zekâ; Türkiye kültürü.

\title{
Parental Attitudes and Emotional Intelligence in Adolescences: The Mediating Role of Self Esteem
}

\begin{abstract}
The present study examined the relationship between parenting styles, self-esteem and emotional intelligence in a sample of 233 adolescents (125 females and 108 males). The variables were measured using Parental Attitude Scale, Rosenberg Self Esteem Scale and Bar-On Emotional Intelligence Scale and demographic information form. For the analysis of the data, firstly the relations between the variables of the research were examined by Pearson Moments Product correlations. Then, the mediating effects of self-esteem between parental attitudes on emotional intelligence were investigated. Consistent with the expectations, there were significant associations between the variables of the study. Moreover, self-esteem partially mediated the relationship between both democratic and authoritarian style and emotional intelligence. However, the results were insignificant for overprotective parenting style. The results were discussed in terms of the relevant literature.
\end{abstract}

Keywords: Parental attitudes; Parenting styles; Self-esteem; Emotional intelligence; Adolescence; Turkish culture.

\section{Extended Summary}

\section{Purpose}

Self-esteem has been a very popular concept in literature. For that reason, variety of definitions and models were proposed to investigate it. In most of these definitions, self-esteem is generally considered as a cognitive evaluation of one's self. These evaluations may be about one's skills or abilities as well as one's social affiliations resulting from his/her group memberships. Different from this view, the affective models explain the concept of self-esteem depending on the persons' feelings about oneself which is mostly based on the relationship established with parents or caregivers in childhood. From this point of view, self-esteem occurs with two types of feelings gained in 
childhood: belonging and exploring. Where belonging is related to feeling of unconditional love, exploring is associated with the feeling that one has an impact on the world. As a result, this view explains self-esteem mostly based on parent-child relationship, rather than a cognitive evaluation (Baumeister, Campbell, Krueger and Vohs, 2003; Brown, 1998; Hewitt, 2009).

Variety of researches confirmed this association by demonstrating the relationship between parenting styles and self-esteem (Ceral ve Dağ, 2005). Moreover, cental role of self-esteem in individuals' emotions is studied by several researchers. Specifically, these studies have demonstrated that individuals with high and low self-esteem differentiate in experiencing positive vs. negative emotions, coping with negative emotions or using affect as information provider as well as emotional intelligence (Harber, 2005; Leary, Tambor, Terdal and Downs, 1995; Schutte, Malouff, Simunek, McKenley and Hollander, 2002; Smith and Petty, 1995).

The purpose of this study is to investigate the associations between parenting styles, self-esteem and emotional intelligence in Turkish adolescences depending on the earlier research results. While previous studies have shown the relationships between parenting styles with these variables, there has been no study showing the indirect links among them in Turkish adolescence in authors' knowledge. Thus, the purpose of this study is to examine the direct and indirect links among them. Specifically, the mediating role of self-esteem between parenting styles and emotional intelligence is explored.

\section{Method}

This study was carried out using relational survey model. The sample is composed of 233 adolescents (125 females and 108 males) who are currently students in a private school located in Kadıköy, İstanbul. The variables were measured using Parental Attitude Scale, Rosenberg Self Esteem Scale and Bar-On Emotional Intelligence Scale and demographic information form.

\section{Results}

Firstly, the relationships among the variables of the research were examined by Pearson Product Moments Correlations. Then, the mediating effects of self-esteem between parental attitudes and emotional intelligence were investigated by AMOS. The results are briefly explained as below:

1. Pearson Product-Moment Correlation was performed as an attempt to determine the relationship between variables of parental styles (democratic, 
authoritarian, self-esteem and emotional intelligence. The results confirmed the expectations by demonstrating the correlations between most of the variables which ranged .14 to .60 .

2. The mediating role of self-esteem between democratic parenting style and self-esteem was investigated with AMOS. The findings regarding alternative fit values of the model indicate that the goodness of fit values $(\chi 2=1357.699, \chi 2 / \mathrm{df}=1.612, \mathrm{RMSEA}=0.051, \mathrm{CFI}=0.878, \mathrm{GFI}=0.784, \mathrm{SRMR}$ $.0623)$ are acceptable. The democratic parental attitude affected emotional intelligence variable (.593), whereas the authoritarian attitude was affected by the emotional intelligence variable (.380) when the self-esteem between democratic and emotional intelligence was taken into account. This parameter value $(p<0.05)$ was found to be significant. It is found that the value of selfesteem falls from the value of (.59) to the value of (.380), which shows the partial mediation between democratic parental attitude and emotional intelligence.

3. The mediating role of self-esteem between authoritarian parenting style and self-esteem was investigated with AMOS. The findings regarding alternative fit values of the model indicate that the goodness of fit values $(\chi 2=872.471, \chi 2 / \mathrm{df}=1.821, \mathrm{RMSEA}=.060, \mathrm{CFI}=.867, \mathrm{GFI}=.813$, SRMR $.0597)$ are acceptable. The authoritarian parental attitude affected the emotional intelligence variable (-.551), while the authoritarian attitude affected the emotional intelligence variable (.329) when the self-esteem between authoritarian attitude and emotional intelligence was taken into account. This parameter value $(p<0.05)$ was found to be significant. It was found that self-esteem decreased the value from -.55 to -.329 which shows the partial mediation between the authoritarian parental attitude and emotional intelligence.

4. Since the effect of the protective parental attitude variable on emotional intelligence was not significant, it was also not possible to look at the mediating effect because the protective parental attitude had an effect on selfesteem $(p>0.05)$.

\section{Discussion and Conclusion}

The purpose of this study is to investigate the direct and indirect links parental attitudes and emotional intelligence via self-esteem in Turkish adolescences. The analysis performed for democratic parental attitude s demonstrated significant positive direct effects for self-esteem and emotional 
intelligence. Moreover, self-esteem partially mediated this relationship. This result confirmed the expectations of the study by showing the partial mediation of self-esteem. Moreover the positive relationships between democratic parental attitudes, self-esteem and emotional intelligence were consistent between earlier research (Aktaş, 2011; Ceral and Dağ, 2005; Mogonea and Mogonea, 2014). The analysis performed for authoritarian parenting style demonstrated that while authoritarian parenting was negatively related with self-esteem, self-esteem was positively related with emotional intelligence consistent with the earlier research and expectations (Nastasa and Sala, 2012). Moreover, self-esteem was found as a partial mediator between authoritarian parenting style and emotional intelligence. To summarize self-esteem partially mediated the relationship between both democratic parenting style and authoritarian parenting style and emotional intelligence. This result shows that besides parenting styles, self-esteem has an important role in explaining the emotional intelligence concept. Therefore, this result may have practical implications for adolescents. Thus, increasing self-esteem in several ways like success, sports, peer acceptance in adolescence might result in increase in emotional intelligence of adolescents.

The analysis for overprotective parenting style was insignificant. Although there are similar findings showing the insignificant relationship between overprotecting parenting style and self (i.e., Sezer, 2010) in Turkey, we believe that more research is needed in order to understand this issue better.

Finally, there are some limitations of this study. The sample is composed of 5, 6, 7, and 8. grade students whose ages differed 10 to 15 in a private high school. For that reason, their developmental stage might be heterogeneous which might affect the generalizability. Later studies may focus on more homogeneous subjects. Moreover, they come from middle-high or high socioeconomic status families. Therefore, later studies may be carried on subjects from different socioeconomic status in order to understand these issues better for Turkish culture.

\section{Giriș}

Benlik saygısı konusunda geniş bir alanyazın ve tanım çeşitliliği mevcuttur. Bu tanımların bir bölümünde benlik saygısı, kişinin benliği hakkındaki bilişsel değerlendirmesi temelinde ele alınmaktadır. Söz edilen değerlendirmeler kişinin çeşitli becerilerine ya da yeteneklerine ilişkin olabileceği gibi grup üyeliklerinden kaynaklanan sosyal âidiyetlerine ilişkin de olabilir. Benlik 
saygısını bilişsel bir değerlendirme olarak ele alan söz konusu tanımların yanı sıra, kavramı açıklayan duyuşsal modeller de mevcuttur. Duyuşsal modellere göre benlik saygısının temeli kişinin çocukluk yıllarında bakım verenleri ile kurulan ilişkilerle atılır. Bu nedenle bu modeller benlik saygısını, kişinin kendisi hakkında verdiği bilişsel bir karar olarak değil, kişinin kendisi hakkında hissettikleri temelinde kavramsallaştırırlar (Baumeister, Campbell, Krueger, ve Vohs, 2003; Brown, 1998; Hewitt, 2009).

Sözü edilen ebeveyn çocuk ilişkisi ve benlik saygısı bağlantısını ebeveyn tutumları temelinde ortaya koyan geniş sayıda araştırma mevcuttur (Aktaş, 2011; Ceral ve Dağ, 2005; Martínez, Garcia ve Yubero, 2007; Mogonea ve Mogonea, 2014). Ebeveyn tutumları ve benlik saygısı arasındaki bu bağlantı, söz konusu tutumların kişinin kendisi hakkındaki duyguları üzerinde ve genel olarak duyguları deneyimlemesi üzerinde belirleyici olmasından kaynaklanabilir. Nitekim benlik saygısı ve kişilerin duygusal deneyimlerinin ilişkili olduğu çeşitli araştırmacılar tarafından gösterilmiştir. Örneğin, Brown ve Marshall (2001), benlik saygisı ile olumlu ve olumsuz duygusal durumları deneyimleme arasındaki ilişkileri ortaya koymuşlardır. Araştırmacılar benlikle ilgili duygusal durumların benlik saygısının en iyi yordayıcıları olduğunu belirtmişlerdir. Araştırmalarında, benlik saygısı yüksek olan insanların düşük olan kişilere göre başarısızlıktan sonra kendileri hakkında daha fazla olumlu duygu yaşadıklarını bulmuşladır. Bu sonuçlardan hareketle benlik saygısının duyguları düzenleme üzerinde önemli bir rolü olduğunu aktarmışlardır. Schutte, Malouff, Simunek, McKenley ve Hollander (2002) da olumlu duygu durumu, yüksek benlik saygısı arasındaki ilişkinin yanı sıra söz konusu kavramların bu araştırmada da ele alınan duygusal zekâ ile ilişkili olduğunu ortaya koymuşlardır.

$\mathrm{Bu}$ çalışmada daha önceki yapılan çalışmalardan yola çıkarak benlik saygısının ebeveynlik stilleri ile duygusal zekâ arasındaki aracı rolünün araştırılması amaçlanmaktadır. Yukarıdaki örneklerde belirtildiği gibi çalışmanın değişkenleri arasındaki ilişkileri ayrı ayrı ele alan çalışmalar olmakla birlikte bu değişkenlerin aralarındaki hem doğrudan, hem de dolaylı bağlantıya değinen bir çalışmaya rastlanmamıştır. Özet olarak bu çalışmanın amacı ebeveyn tutumları ve duygusal zekâ arasındaki doğrudan ve dolaylı etkileri benlik sayg1s1 aracılığ1 ile Türkiye'deki ergenler üzerinde incelemektir. Araştırmanın değişkenlerinin özellikle ebeveyn tutumlarının sosyo-kültürel bağlamla ilişkili olduğu (Martinez, Garcia ve Yubero, 2007) düşünüldügünde hem bireyci 
hem de hem de toplulukçu ögeler taşıdığı kabul edilen kültürümüzde (Çukur, De Guzman ve Carlo, 2004) önceki çalışmalarla benzer sonuçların bulunup bulunmayacağ 1 da araştırmanın soruları arasındadır. Bu bölümde bu amaçlar doğrultusunda öncelikle, değişkenler kısaca tanıtılarak aralarındaki ilişkilere ilgili araştırmalardan örnekler verilerek değinilmekte, daha sonra araştırmanın amacı sunulmaktadır.

\section{Ebeveyn Tutumları ve Benlik Saygısı}

Darling ve Steinberg (1993), ebeveyn tutumlarını, ebeveynlerin çocuğa yönelik tutumlarının toplamının aktarılması ile ortaya çıkan duygusal iklim temelinde tanımlamışlardır. Her ebeveyn ve çocuk arasındaki ilişki özgün de olsa, araştırmacılar bu konuda çeşitli sınıflandırmalar ve kavramlar kullanmışlardır. Bu konudaki araştırmalar incelendiğinde demokratik, otoriter, izin verici ve ihmalkâr gibi çeşitli sınıflamaların ya da daha özel davranışlarla ilişkili olan ebeveynlik uygulamalarını kavramının kullanıldığı görülmektedir (Brenner ve Fox, 1999). Bu araştırmada kültürümüzde geliştirilen bir ölçek temelinde demokratik, otoriter ve koruyucu-istekçi ana baba tutumları ele alınmaktadır (Kuzgun ve Eldeleklioğlu, 2005).

Genel olarak, demokratik tutum sergileyen ebeveynler, çocuklarını kabul etme ve isteklerine saygı gösterme eğilimindedirler. Bu tutumda çocuğun beslenme ihtiyacının yanı sıra sevgi ihtiyacı da karşılanır; ayrıca çocuğun bağımsız olması desteklenir (Demiriz ve Öğretir, 2007; Reitman, Rhode, Hubb ve Altobello, 2002). Otoriter tutumun temel özelliği ebeveynlerin çocuğu aşırı baskı altında tutmaları, onu şekillendirmeye ve denetlemeye çalışmalarıdır. $\mathrm{Bu}$ tip ebeveyn tutumunda kurallar konulurken hiçbir açıklama yapılmaz ve çocuğun da bu kurallara sorgusuz sualsiz uyması beklenir. Ayrıca, çocuğun her türlü özerklik ve bağımsızlık girişimleri otoriter ebeveyn tarafından başına buyrukluk ve itaatsizlik olarak algılanır (Özgüven, 2001; Şendil, 2003). Koruyucu-istekçi tutum ise çocuğu sürekli korumayı, onun yapabileceği en basit işi bile ebeveynin yapıp çocuğa sorumluluk verilmemesini içerir. Çocukların iyiliği için çocuklar adına kararlar alınır ve çocuğun bağımsızlaşması hoş karş1lanmaz (Kulaksızoğlu, 2011; Yörükoğlu, 1990).

Yukarıda aktarılan farklı ebeveyn tutumları Driscoll'un (2013) belirttiği gibi çocukluk ya da erken ergenlik döneminde bireyin benlik saygısı düzeyini olumlu ya da olumsuz etkileyebilir. Benlik saygısının gelişimi açısından bakıldığında demokratik tutum, ait olma ve keşfetme duygularını en fazla karşılar görünmektedir. Diğer yandan otoriter ve koruyucu istekçi tutumların 
ise söz konusu gereksinimleri düşük düzeyde karşıladıkları düşünülebilir. Söz edilen ilişkiyi inceleyen çok sayıda araştırma da demokratik tutumun yüksek benlik saygisı ile koruyucu, otoriter ya da izin verici olarak isimlendirilen ebeveyn tutumlarının ise düşük benlik saygısı ile ilişkili olduğunu göstermektedir (Aktaş, 2011; Ceral ve Dağ, 2005; Driscoll, 2013; Mogonea ve Mogonea, 2014).

$\mathrm{Bu}$ çalışmada ilgili araştırma bulguları ile tutarlı olarak demokratik tutumun yüksek benlik saygısı ile otoriter ve koruyucu-istekçi ana baba tutumlarının ise düşük düzeyde benlik saygısı ile ilişkili olması beklenmektedir.

\section{Ebeveyn Tutumları ve Duygusal Zekâ}

Demokratik ebeveynliğin ya da ebeveynin sıcaklığını vurgulayan ebeveyn tutumlarının diğer psikososyal değişkenler gibi duygusal zekâ ile de olumlu yönde ilişkili olduğunu gösteren çalışmalar sayıca sınırlı da olsa mevcuttur. Örneğin, Abdollahi, Abu Talib ve Motalebi (2013), İranlı erkek ergenler üzerinde yapmış olduğu çalışmada, sevgi veren ve kısıtlayan ile optimal ebeveynlik stilinin yüksek duygusal zekâ becerisinin güçlü bir yordayıcısı olduğunu bulmuşlar, diğer yandan sevgisiz kontrol eden ve ihmal edici stilin ise ergenlerdeki duygusal zekâ becerisinin düşük bir yordayıcısı olduğunu bulmuşlardır. Bu noktadan hareketle, araştırmacılar duygusal zekâ gelişiminde sevginin temel bir rol oynadığını belirtmişlerdir. Nastasa ve Sala da (2012) ergenlerde söz konusu ilişkiyi araştırmışlar, izin verici ve demokratik stilin duygusal zekâ ile olumlu, diğer yandan otoriter ve baskıcı stillerle ise olumuz yönde ilişkili olduğunu ortaya koymuşlardır. Alegre (2011) de ebeveynlerin yanıt verebilirliğinin, duygusal açıdan rehber olabilmelerinin çocuklarda yüksek duygusal zekâ ile ilişkili olduğunu bulmuşlardır. Aktarılan araştırmalara dayanarak bu araştırmada da demokratik tutumun diğer tutumlara göre duygusal zekâ ile olumlu yönde ilişkili olması beklenmektedir.

\section{Benlik Saygısı ve Duygusal Zekâ}

Benlik saygısı konusunda, yüksek benlik saygısının benlik kavramında netlik gibi (Campbell, 1990; Usborne ve Taylor, 2010) olumlu psikososyal değişkenlerle ve düşük benlik saygısının anti sosyal davranış, saldırganlık ve suç gibi olumsuz psikososyal değişkenlerle ilişkisini gösteren çalışmalar mevcuttur (Donnellan, Trzesniewski, Robins, Moffitt and Caspi, 2005). Trzesniewski, Donnellan, Moffitt, Robins, Poulton ve Caspi (2006) benlik saygis1 düşük olan ergenleri yüksek olanlarla karşılaştırmışlardır. Ergenlerdeki düşük benlik saygısının olumsuz zihinsel ve fiziksel sağlık, yetişkinlikte suç işleme 
ve sınırlı ekonomik beklenti içinde olma gibi birçok olumsuz psikososyal değişkenin yordayıcısı olduğunu ortaya koymuşlardır.

Diğer yandan benlik saygısının yüksekliğinin avantajlı olduğuna ilişkin bu yaygın görüşü doğrulamayan çalışmalar da mevcuttur. Örneğin, Baumeister, Champell, Krueger ve Vohls (2003) çalışmalarında yüksek benlik sayg1sının okuldaki başarı, sevilme, çekici bulunma, daha iyi ilişkiler kurma gibi olumlu değişkenlerle ilişkili olmadığını göstermişlerdir. Ayrıca, yüksek benlik saygısının sigara içme, içki içme, madde kullanımı ve erken yaşta yaşanan cinsellik gibi riskli davranışlar konusunda da koruyucu etkisinin olmadığı bulunmuştur. Yine, yüksek benlik saygısının yüksek iç grup tarafgirliği, kendini düzenleme başarısızlığ 1 gibi olumsuz psikososyal değişkenlerle ilişkilerini ortaya koyan çalışmalar da vardır (Lambird ve Mann, 2006; Verkuyten ve Hagendoorn, 2002).

Baumeister ve arkadaşları (2003), yüksek benlik saygısının sanıldığı gibi somut kriterler açısından avantaj sağlamadığını ancak iyi ve mutlu hissetme gibi olumlu duyguları deneyimleme açısından kişilere avantaj sağladığını ortaya koymuştur. Benzer biçimde Hewitt (2009) de yüksek benlik saygisının olumlu yönünün somut faktörlerden ziyade mutluluk ve zihin sağlığ değişkenleri ile olumlu ilişkisi olduğunu aktarmıştır. Leary, Tambor, Terdal ve Downs'ın (1995) aktardığı gibi insanların benlik saygısı için çabalarının nedeni kavramın olumlu duyguyu geliştirmesi ve kişileri stres ve diğer olumsuz duygulardan koruması olabilir. Greenberg, Solomon, Pyszczynski, Rosenblatt, Burling, Lyon, Simon ve Pinel (1992) bu konuda yürüttükleri üç çalışmada benlik saygısının kaygıya karşı tampon görevi yaparak koruyucu bir etkisi olduğunu göstermişlerdir. Smith ve Petty (1995) de benlik saygısı ve duygu arasındaki ilişkiyi ele almışlardır ve çalışmalarında benlik saygısı ile olumsuz duygusal durumları düzenleme arasında güçlü bir ilişki olduğunu ortaya koymuşlardır. Benlik saygısı düşük olan bireyler duygu durumları olumsuz olduğunda olumsuz düşünce ve anılara yatkın olurken, benlik saygısı yüksek olan bireyler olumsuz duygularının tam aksi yönde düşünerek keyifsiz duygularını azaltma eğilimi göstermişlerdir.

Duygu düzenlemenin yanı sıra yüksek ve düşük benlik saygısına sahip bireyler kendi duyguları hakkında bilgi sahibi olma düzeyleri açısından da farklılık göstermektedirler. Bu konuda Harber'ın (2005) aktardığı gibi, duygusal-bilgi (affect-information) modeline göre insanlar duygularına dikkat edip onu bilgi sağlayıcı olarak gördüklerinde birçok avantaj elde edebilirler. 
Bunlar daha iyi seçimler yapabilme, zorlu görevlere daha iyi adapte olabilme, daha doyum sağlayıcı sosyal bağlar kurabilme gibi olumlu sonuçlar olabilir. Harber (2005), benlik saygısı ve duyguyu bilgi sağlama aracı olarak görme arasındaki bağlantıyı araştırmış ve farklı düzeyde benlik saygısına sahip olan insanların duyguyu bilgi olarak kullanmada farklılık gösterdiğini ortaya koymuştur. Diğer bir ifadeyle yüksek benlik saygısına sahip olan insanların kendi duygularına daha fazla inandıklarını ve bilgi sağlayıcı olarak gördüklerini belirtmiştir.

Buraya kadar aktarılan sonuçlar yüksek benlik saygısının daha fazla olumlu duygu deneyimleme, duyguyu daha iyi düzenleme, duyguyu bilgi sağlayıcı olarak kullanabilme gibi alanlarda avantaj sağlayıcı bir kavram olduğunu göstermektedir. Söz edilen duygusal avantajlar yüksek duygusal zekâ ile de ilişkili olabilir.

Salovey ve Mayer (1990) duygusal zekâyı, kişinin kendisinin ve başkalarının duygularını gözlemleyebilme, onları birbirinden ayırt edebilme ve bu bilgiyi düşünce ve davranışlarına rehber olarak kullanabilmeyi içeren bir sosyal zekâ türü olarak ele almışlardır. Bu çalışmada da temel alınan duygusal zekâyı Bar-On (2006), bireyin kendisini ve diğerlerini anlamasını, kişilerle ilişki kurmasını ve o anda içinde bulunduğu çevreye uyum sağlayıp o çevre ile baş etmeyi sağlayan yetenekler olarak ifade etmiştir. Yüksek benlik sayg1sına sahip olan kişinin olumlu duygu durumu ve duyguyu bilgi olarak kullanabilme becerisi nedeniyle duygusal zekâ düzeyinin de yüksek olabileceği düşünülebilir.

Duygusal zekâ ve benlik saygısının hem ergenlerde hem de yetişkinlerde ilişkili olduğunu gösteren çalışmalar mevcuttur (Rey, Extremera ve Mario Pena, 2011; Schutte, Malouff, Simunek, McKenley ve Hollander, 2002). $\mathrm{Bu}$ araştırmada da benlik saygısı ve duygusal zekâ arasında olumlu bir ilişki olması beklenmektedir.

\section{Araştırmanın Amacı}

Buraya kadar aktarılan araştırma sonuçları çalışmanın değişkenleri olan ebeveyn tutumları, benlik saygısı ve duygusal zekâ arasındaki ilişkileri ortaya koymaktadır. Bu çalışmada önceki çalışmaların bulgularının ışı̆̆ında, ergenlik döneminde ebeveyn tutumları ve duygusal zekâları arasındaki direk ve dolaylı etkiler incelenmekte ve benlik saygısı aracı değişken olarak düşünülmektedir. $\mathrm{Bu}$ çalışma ile benlik saygısının söz konusu kavramların incelenmesindeki 
rolünün belirginleşeceği düşünülmektedir. Çünkü çocuk ve ergenlerin psikososyal gelişiminde ebeveyn tutumlarını değiştirmek oldukça güçtür. Ancak özellikle birçok fiziksel, bilişsel, toplumsal ve duygusal değişimin yaşandığı ve ebeveynler dışında diğer sosyal ajanların önem kazandığı ergenlik döneminde benlik saygısını ebeveyn tutumu dışındaki faktörlerle ve ilişkilerle arttırmak mümkündür. Benlik saygısının artması duygusal zekânın ve buna bağlı olacak birçok psikososyal değişkenin olumlu yönde artmasında da önemli olabilir. Bu anlamda ergenlerde söz konusu aracı etkinin incelenmesinin hem teorik hem de pratik açıdan yararlı olacağı düşünülmektedir.

Çocukluktaki ebeveyn tutumlarının duygusal bir ortam oluşturarak kişinin kendisine ilişkin benlik saygısı ve duygusal zekâsı üzerinde belirleyici olacağı düşünülmektedir. Aktarılan araştırma örneklerine dayanarak ve demokratik ebeveyn tutumunun benlik saygısının gelişiminde belirleyici olan ait olma ve keşfetme duygularını en fazla karşıladığı düşünülerek, yüksek benlik saygısı ile ilişkili olması beklenmektedir. Diğer yandan önceki araştırmalarla tutarlı olarak otoriter ve koruyucu-istekçi tutumların ise düşük düzeyde benlik saygısı ile ilişkili olması beklenmektedir (Aktaş, 2011; Brown, 1998; Ceral ve Dağ, 2005; Mogonea ve Mogonea, 2014). Benzer biçimde önceki araştırma sonuçlarının ve duygusal zekânın gelişiminde sevginin önemini vurgulayan çalışmalara dayanarak demokratik ebeveyn tutumunun yüksek duygusal zekâ ile, diğer tutumların ise daha düşük düzeyde duygusal zekâ ile ilişkili olması beklenmektedir (Abdollahi, Abu Talib ve Motalebi, 2013; Nastasa ve Sala, 2012). Aracı değişken olan benlik saygısı ise giriş bölümünde aktarıldığı gibi bilişsel bir karardan ziyâde kişinin kendisine ilişkin duygusu olarak düşünülmektedir. Kavramın duygusal zekâ ile ilişkili kavramlar olan duyguları tanıma ve bilgi verici olarak kullanma, duyguları düzenleyebilme gibi duygusal zekâ ile ilişkili olan değişkenlerle bağlantılı olduğunu gösteren araştırmalar mevcuttur (Harber, 2005; Smith ve Petty, 1995). Bu bağlamda bu araştırmada çocuklukta farklı ebeveyn tutumları ile oluşan duygusal iklimin kişinin benlik saygısında belirleyici olacağı ve benlik saygısının da duygusal zekâ ile bağlantılı olacağı düşünülmektedir. Özet olarak bu çalışmada yüksek düzeyde demokratik ebeveyn tutumunun hem direk hem benlik saygısı aracılığı ile dolaylı olarak yüksek duygusal zekâ düzeyi ile ilişkili olması beklenmektedir.

Buraya kadar sunulan bilgiler 1şığında araştırmanın hipotezleri aşağıdaki gibi oluşturulmuştur:

1. Ergenlerin benlik saygis1, demokratik ebeveyn tutumu ile olumlu 
yönde, otoriter ve koruyucu-istekçi tutumlarla ise olumsuz yönde ilișkilidir.

2. Ergenlerin duygusal zekâ düzeyi demokratik ebeveyn tutumu ile olumlu yönde, otoriter ve koruyucu-istekçi tutumlarla ise olumsuz yönde ilişkilidir.

3. Demokratik ebeveyn tutumu, yüksek benlik saygısı aracıllığı ile duygusal zekâ düzeyini olumlu yönde etkileyecektir. Diğer yandan otoriter ve koruyucu-istekçi ebeveyn tutumları ise düşük benlik saygısı aracılığ 1 ile ergenin duygusal zekâsını olumsuz yönde etkileyecektir.

\section{Yöntem}

Araştırmada ortaokul düzeyindeki ergenlerin algıladıkları ebeveyn tutumlarının benlik saygıları ve duygusal zekâları üzerindeki etkisini incelemek amacıyla, ilişkisel tarama modeli kullanılmıştır. İlişkisel tarama modeli, iki ve daha çok sayıdaki değişken arasında birlikte değişim varlığını veya derecesini belirlemeyi amaçlayan araştırma modelidir (Karasar, 2010).

\section{Evren ve Örneklem}

Çalışma 2015-2016 eğitim öğretim yılının Mayıs ayında, yaşları 10 ile 15 arasında değişmekte olan, 125'i (\%53.6) kız ve 108'i (\%46.4) erkek olmak üzere toplam 233 katılımcı ile yapılmıştır. Katılımcıların yaş ortalaması $12.03 \pm 1.11$ 'dir.

Araştırma evrenini İstanbul'da Kadıköy ilçesinde yaşayan MEB'e bağlı özel bir okula devam eden 5, 6, 7 ve 8. sinıf öğrencileri oluşturmuştur. 320 katılımcı ile yürütülen çalışmada Bar-On Duygusal Zekâ Ölçeğinin 88. maddesi olan "Yukarıdaki ifadelere samimi bir şekilde cevap verdim." maddesini 'Kesinlikle Katıliyorum' ve 'Katılıyorum' maddesini işaretlemiş olanlar değerlendirmeye alınmıştır.

\section{Veri Toplama Araçları}

İl millî eğitim müdürlüğünden gerekli izinler alındıktan sonra çalışmalara başlanmıştır. Katılımcılara, Kişisel Bilgi Formu, Anne-Baba Tutum Ö1çeği, Rosenberg Benlik Saygısı Ölçeği ve Bar-On Duygusal Zekâ Ölçeği uygulanmıştır.

Kişisel Bilgi Formu: Örneklemi oluşturan katılımcıları çeşitli yönleri ile tanımak amacıyla hazırlanan form sekiz sorudan oluşmaktadır. Form sırasıyla, yaş, cinsiyet, sınıf, ailede kaçıncı çocuk, babanın eğitim durumu, annenin 
eğitim durumu, anne babanın medenî durumu, sosyo-ekonomik düzey sorularını içermektedir.

Rosenberg Benlik Saygısı Ölçeği: Rosenberg (1965) tarafından geliştirilmiş ergenlerin benlik saygılarını ölçmeyi hedefleyen bir ölçme aracıdır. 63 maddeden oluşan ölçeğin 12 alt ölçeği vardır. Bunlar benlik saygısı, kendilik kavramının sürekliliği, insanlara güvenme, eleştiriye duyarlılık, depresif duygulanım, hayalperestlik, psikosomatik bilgiler, kişiler arası ilişkilerde tehdit hissetme, tartışmalara katılabilme derecesi, ana-baba ilgisi, baba ile ilişki, psişik izolasyondur. Araştırmanın amacı doğrultusunda benlik saygısını ölçmeye yönelik olan ölçeğin "benlik saygısı" alt ölçeği kullanılmıştır. Envanterde 10 madde yer almaktadır. Likert tipi bir ölçektir. Çuhadaroğlu (1986) tarafından Türkçeye uyarlanan ölçeğin güvenirlik katsayısı 0.75 , geçerlik katsayısı ise 0.71'dir. Ölçeğin yaş sınırlaması yoktur (akt; Balat ve Akman 2004).

Bu çalışmada ölçek için doğrulayıcı faktör analizi yapılmıştır. Doğrulayıcı madde arasında model test değerleri $\mathrm{x}^{2}(8.927), \mathrm{x}^{2} / \mathrm{df}(1.785)$ olduğundan DFA'nın anlamlı olduğu anlaşılmaktadır. Model $p$ değeri $(p<0.05)$ bulunmuştur. Ayrıca uyum indeks değerleri GFI (.085), CFI (985), SRMR (.03) RMSEA (.058) kabul edilebilir sınırlar içinde olduğundan DFA sonucunun kullanılabilir olduğu anlaşılmıştır. Bu çalışmada ölçeğin Cronbach Alfa iç tutarlılık katsayısı .75 olarak hesaplanmıştır.

Anne-Baba Tutum Ölçeği: Algılanan ebeveyn tutumlarını ölçmek amacı ile Kuzgun (1972) tarafindan geliştirilmiş ve Eldeleklioğlu (1993) tarafından revize edilmiş, demokratik anne-baba tutumu, otoriter anne-baba tutumu, koruyucu-istekçi anne baba tutumu olmak üzere üç ana alt boyuttan ve toplam 40 maddeden oluşan bir ölçektir. Ölçek, 5'li likert tipi ölçektir. Ölçekteki derecelendirme, Hiç Uygun Değil (1), Pek Uygun Değil (2), Biraz Uygun (3), Çok Uygun (4), Tamamen Uygun (5) şeklinde düzenlenmiştir. Demokratik tutum iç tutarlılık katsayısı 0.89, kararlılık katsayısı 0.92; koruyucu / istekçi tutum iç tutarlılık katsayısı 0.82 , kararlılık katsayısı 0.75 ; otoriter tutum iç tutarlılık katsayısı 0.78 kararlılık katsayısı 0.79 olarak belirlenmiştir. Ölçekler arası korelasyon katsayıları, demokratik ile koruyucu istekçi tutum; -0.13, demokratik ile otoriter tutum; -0.64 , otoriter ile koruyucu-istekçi tutum; -0.36 olarak bulunmuştur (akt; Kuzgun ve Eldeklioğlu, 2005).

Bu çalışma için ölçeğe doğrulayıcı faktör analizi yapılmış ve ölçeğin 3 faktörlü yapısı alanyazında geçtiği gibi aynen korunmuştur. 1. düzey doğrulay1cı faktör analizi sonucu $\mathrm{x}^{2}(403.940)$ ve $\mathrm{x}^{2} / \mathrm{df}$ (1.388) bulunduğundan DFA 
yapısı geçerli bulunmuştur. Model $p$ değeri $(p<0.05)$ olarak bulunmuştur. Model fit indexlerinden GFI (.883), CFI (.945) ve RMSEA (0.041) bulunduğundan model kabul sınırları dahilinde yer almaktadır. Model genelinin bir testi olan standart RMR index değeri ise 0.0590 olarak tespit edilmiştir. Bu çalışmada ölçeğin Cronbach Alfa iç tutarlılık katsayısı, demokratik tutum alt boyutu için .89 , otoriter tutum alt boyutu için .60 ve koruyucu-istekçi tutum alt boyutu için ise .83 olarak hesaplanmıştır.

Bar-On Duygusal Zekâ Ölçeği: Dr. Reuven Bar-On (1997) tarafından geliştirilen ve duygusal zekâ boyutlarını ölçen 133 maddelik bir ölçme aracıdır. Türkçe dilsel eşdeğerlik, güvenirlik ve geçerlik çalışması Çuhadaroğlu (2002) tarafindan yapılmıştır. Ölçek, 5'li likert tipi ölçektir. Ölçekte derecelendirme; Tamamen Katıliyorum (1), Kat1liyorum (2), Kararsızım (3), Katılmıyorum (4), Kesinlikle Katılmıyorum (5) şeklinde yapılmıştır. 15 duygusal zekâ boyutunun gruplandırıldığ, 5 ana boyuttan oluşan ölçekte her boyut kendi içerisinde iki ile beş arasında değişen alt ölçeğe ayrılmıştır. Bu boyutlar; kişisel farkındalık, kişilerarası ilişkiler, strese tolerans, şartlara ve çevreye uyum ve genel ruh hali alt boyutlarıdır. Ölçeğin Türkçeye uyarlama çalışmaları Mumcuoğlu (2002) tarafindan gerçekleştirilerek ölçek 87 maddeye düşürülmüştür. 87 maddelik anketin toplam boyutları itibariyle Cronbach Alfa katsayıs .92.12 olup kabul edilebilir düzeydedir. Temel alt boyutlarından kişisel yetenekler boyutu $.83,73$; kişilerarası ilişkiler alt boyutu .77,87; uyumluluk boyutu $.65,42$; stresle başa çıkma boyutu .73,14; genel ruh durumu .75,06 olup, kabul edilebilir düzeydedirler. Ölçeğe eklenen 88. madde ise "Yukarıdaki ifadelere samimi bir şekilde cevap verdim." ifadesini içermektedir ve örneklem seçiminde bu maddeye 'Kesinlikle Katılıyorum' ve 'Katılıyorum' maddesini işaretlemiş olan katılımcılar değerlendirmeye alınmıştır (akt; Karabulut, 2012).

Ölçek üniversite öğrencilerinden oluşan bir örneklemle geliştirilmiştir. Bu araştırmada da ölçeğin ergenler üzerinde de güvenilir ve geçerli kabul edilebileceği gösterilmektedir. Bu amaç doğrultusunda bu çalışma için ölçeğe doğrulayıcı faktör analizi yapılmış ve 5 faktörlü yapısı alanyazında geçtiği gibi aynen korunmuştur. 2. düzey doğrulayıcı faktör analizi sonucu $\mathrm{x}^{2}(437.696)$ ve $\mathrm{x}^{2} / \mathrm{df}(2.036)$ bulunduğundan DFA yapısı geçerli bulunmuştur. Model $\mathrm{p}$ değeri $(p<0.05)$ olarak bulunmuştur. Model fit indexlerinden GFI (.851), CFI (.904) ve RMSEA (0.067) bulunduğundan model kabul sinırları dahilinde yer almaktadır. Model genelinin bir testi olan standart RMR index değeri ise 0.0561 olarak tespit edilmiştir. 2. düzey doğrulayıcı faktör analizi 
yapıldığı için Cronbach Alfa iç tutarlı1ık katsayısı elde edilen tek faktörlü yapı için yapılmış ve .93 olarak bulunmuştur.

\section{İşlem}

Uygulama Mayıs-Haziran 2016 tarihleri arasında, iki hafta süresince yapılmıştır. İstanbul İl Millî Eğitim Müdürlüğü’nden ölçek uygulama izinleri alınmıştır. Kadıköy ilçesine bağlı özel bir ilköğretim okulunda görev yapan idarecilere, yürütülecek olan çalışma ile ilgili bilgiler verilip izinler alındıktan sonra çalışmaya başlanmıştır. Uygulama yaklaşık 50 dakika sürmüştür. Her uygulamadan önce, katılımcıların cevaplamaları içtenlikle yapmaları için araştırmanın amacı ve önemi anlatılmış ayrıca kişisel bilgilerin ve verilerin gizlilik ilkesine bağlı kalınarak analiz edileceği belirtilmiştir.

\section{Bulgular}

Bu bölümde öncelikle araştırmanın değişkenleri arasındaki ilişkiler Pearson Momentler Çarpım Korelasyonu ile incelenmiştir. Değişkenler arasındaki korelasyon değerleri Tablo 1'de sunulmuştur. Daha sonra, ebeveyn tutumlarının duygusal zekâ üzerinde benlik saygısının aracı etkisi araştırılırken öncelikle araştırmanın değişkenleri arasındaki tekil ilişkiler incelenmiştir, daha sonra her bir ebeveyn durumu için ayrı ayrı aracılık modellenmiştir. Sözü edilen aracılık testleri için katsayı değerleri Tablo 2, 3 ve 4 'te sunulmuştur.

Tablo 1. Değişkenler Arasındaki Pearson Momentler Çarpımı Korelasyon Değerleri

\begin{tabular}{lccccc}
\hline Değişken & 1 & 2 & 3 & 4 & 5 \\
\hline Benlik Saygısı & 1 & $.32^{* *}$ & $-.25^{* *}$ & -.067 & $.60^{* *}$ \\
Demokratik Tutum & $.32^{* *}$ & 1 & $-.60^{* *}$ & $-.25^{* *}$ & $.55^{* *}$ \\
Otoriter Tutum & $-.25^{* *}$ & $-.60^{* *}$ & 1 & $.38^{* *}$ & $-.40^{* *}$ \\
Koruyucu-İstekçi Tutum & -.07 & $-.25^{* *}$ & $.38^{* *}$ & 1 & $-.14^{*}$ \\
Duygusal Zekâ & $.60^{* *}$ & $.55^{* *}$ & $-.40^{* *}$ & $-.14^{*}$ & 1 \\
\hline$*^{* *}<<.01, *_{p}<.05$ & & & & &
\end{tabular}

Tablo 1'de görüldüğü gibi araştırmanın değişkenleri birbirleri ile anlamlı ilişkiler göstermektedir. Daha sonra, benlik saygısının ebeveyn tutumları ve duygusal zekâ arasındaki aracı etkisinin incelenmesi amacıyla demokratik, otoriter ve koruyucu istekçi tutum için ayrı ayrı analizler yapılmıştır. Aşağıda söz edilen analizler sırasıyla aktarılmaktadır.

\section{Demokratik Ebeveyn Tutumunun Duygusal Zekâ Üzerindeki Etkisinde Benlik Saygısı Değişkeninin Aracılık Rolü}

Demokratik ebeveyn tutumunun duygusal zekâ üzerindeki etkisinde 
benlik saygısı değişkeninin aracılık rolünün araştırıldığı modelde model test değerleri $\mathrm{x}^{2}$ (1357.699), $\mathrm{x}^{2} / \mathrm{df}$ (1.612) bulunduğundan modelin anlamlı olduğu anlaşılmaktadır. Uyum indeks değerleri GFI (.784), CFI (.878), RMSEA (.051) ve SRMR (.0623) bulunduğundan kabul edilebilir sınırlarda olduğu anlaşılmaktadır. Aracılık testi için katsayı değerleri Tablo 2'de gösterilmiştir. Sözü edilen aracılık ilişkisi ise Şekil 1'de gösterilmiştir.

Tablo 2. Aracılık Testi İçin Katsayı Değerleri

\begin{tabular}{llllcccc}
\hline Model & Endojen & Etki & Eksojen & Beta & Std.B & C.R. & p \\
\hline & DZ & $<---$ & demokratik & .799 & .593 & 6.607 & $* * *$ \\
& BS & $<---$ & demokratik & .591 & .394 & 4.845 & $* * *$ \\
& DZ & $<---$ & BS & .649 & .684 & 7.364 & $* * *$ \\
Mediator & BS & $<---$ & demokratik & .577 & .398 & 4.848 & $* * *$ \\
& DZ & $<---$ & BS & .504 & .531 & 6.433 & $* * *$ \\
& DZ & $<---$ & demokratik & $\mathbf{. 5 2 4}$ & $\mathbf{. 3 8 0}$ & $\mathbf{5 . 2 1 6}$ & $* * *$ \\
\hline
\end{tabular}

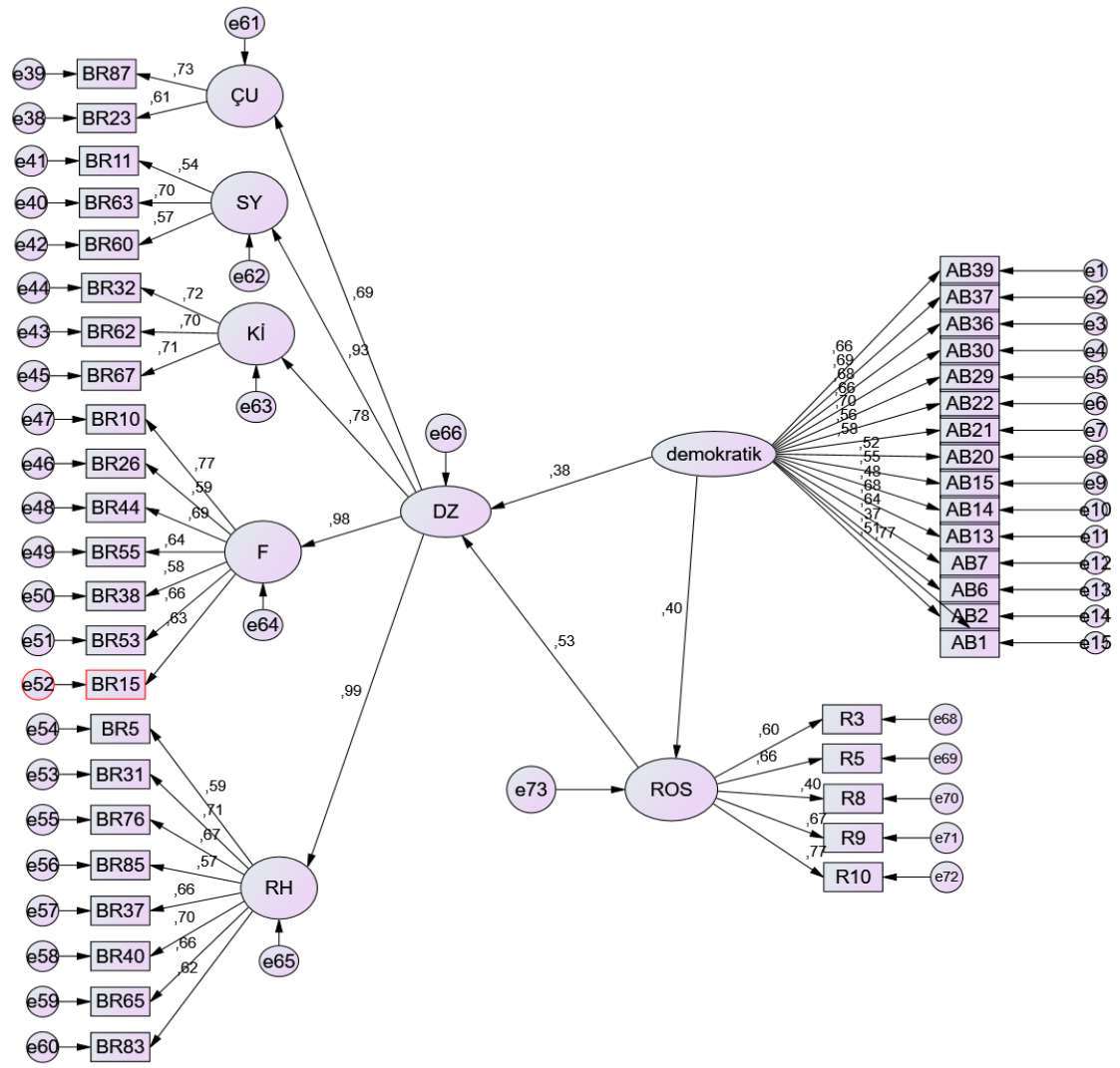

Şekil 1. Demokratik ebeveyn tutumu ile duygusal zekâ ilişkisinde benlik saygisının kısmi-aracı rolü. 
Demokratik ebeveyn tutumu değişkeni tekil ilişkide duygusal zekâ değişkenini (.593) etkilerken, demokratik tutum ile duygusal zekâ arasına benlik saygısı alındığında otoriter tutumun duygusal zekâ değişkenine etkisi (.380) olarak tespit edilmiştir. Bu parametre değeri $(p<0.05)$ anlamlı bulunmuştur. Etki değerinin (.59) değerinden (.380) değerine düşmesi, benlik saygısı değişkeninin demokratik ebeveyn tutumu ile duygusal zekâ arasındaki ilişkide kısmî aracı olduğu anlaşılmıştır.

\section{Otoriter Ebeveyn Tutumunun Duygusal Zekâ Üzerindeki Etki- sinde Benlik Saygısı Değişkeninin Aracılık Rolü}

Otoriter ebeveyn tutumunun duygusal zekâ üzerindeki etkisinde benlik saygıs değişkeninin aracılık rolünün araştırıldığı modelde model test değerleri $\mathrm{x}^{2}(872.471), \mathrm{x}^{2} / \mathrm{df}(1.821)$ bulunduğundan modelin anlamlı olduğu anlaş1maktadır. Uyum indeks değerleri GFI (.813), CFI (.867), RMSEA (.060) ve SRMR (.0597) bulunduğundan kabul edilebilir sınırlarda olduğu anlaşılmaktadır. Otoriter ebeveyn tutumu değişkeni tekil ilişkide duygusal zekâ değişkenini (-.551) etkilerken, otoriter tutum ile duygusal zekâ arasına benlik saygısı alındığında otoriter tutumun duygusal zekâ değişkenine etkisi (.329) olarak tespit edilmiştir. Bu parametre değeri $(p<0.05)$ anlamlı bulunmuştur. Etki değerinin (-.55) değerinden (-.329) değerine düşmesi benlik saygısı değişkeninin otoriter ebeveyn tutumu ile duygusal zekâ arasındaki ilişkide kısmî aracı olduğu anlaşılmıştır. Aracılık testi için katsayı değerleri Tablo 3'de gösterilmiştir. Sözü edilen aracılık ilişkisi ise Şekil 2'de gösterilmiştir.

Tablo 3. Aracılık Testi İçin Katsayı Değerleri

\begin{tabular}{llllcccc}
\hline Model & Endojen & Etki & Eksojen & Beta & Std.B & C.R. & p \\
\hline & DZ & $<---$ & otoriter & -1.325 & -.551 & -4.126 & $* * *$ \\
& ROS & $<---$ & otoriter & -1.129 & -.406 & -3.445 & $* * *$ \\
& DZ & $<---$ & BS & .649 & .684 & 7.364 & $* * *$ \\
Mediator & ROS & $<---$ & otoriter & -1.049 & -.404 & -3.544 & $* * *$ \\
& DZ & $<---$ & BS & .522 & .549 & 6.284 & $* * *$ \\
& DZ & $<---$ & otoriter & $\mathbf{- . 8 1 0}$ & $\mathbf{- . 3 2 9}$ & $\mathbf{- 3 . 3 4 8}$ & $* * *$ \\
\hline
\end{tabular}




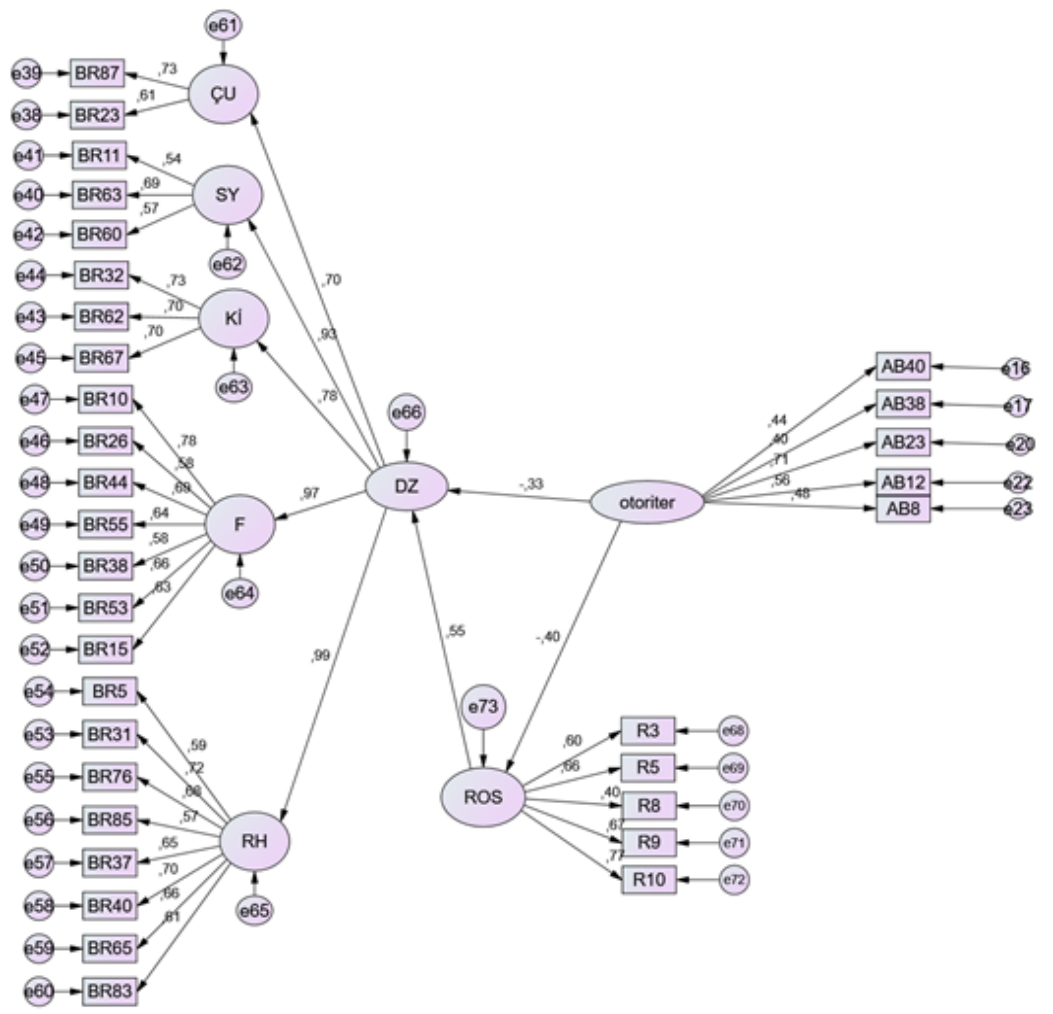

Şekil 2. Otoriter ebeveyn tutumu ile duygusal zekâ ilişkisinde benlik saygıs1nın kısmî-aracı rolü.

Koruyucu anne baba tutumu değişkeninin duygusal zekâya etkisi anlamlı bulunmadığından ayrıca koruyucu anne baba tutumunun benlik sayg1sına etkisi $(p>0.05)$ bulunduğundan arac1lı etkisine bakılması mümkün olmamıştır. Aracılık için gerekli olan varsayımlar sağlanmadığından aracılığa bakılmamıştır. Aracılık testi için katsayı değerleri Tablo 4'de gösterilmiştir.

Tablo 4. Aracılık Testi İçin Katsayı Değerleri

\begin{tabular}{llllllll}
\hline Model & Endojen & Etki & Eksojen & Beta & Std.B & C.R. & P \\
\hline \multirow{5}{*}{ Mediator } & DZ & $<---$ & demokratik & .799 & .593 & 6.607 & $* * *$ \\
& BS & $<---$ & demokratik & .591 & .394 & 4.845 & $* * *$ \\
& DZ & $<---$ & BS & .649 & .684 & 7.364 & $* * *$ \\
& ROS & $<---$ & demokratik & .577 & .398 & 4.848 & $* * *$ \\
& DZ & $<---$ & BS & .504 & .531 & 6.433 & $* * *$ \\
& DZ & $<---$ & demokratik & .524 & .380 & 5.216 & $* * *$ \\
\hline
\end{tabular}




\section{Tartışma}

Bilindiği gibi bu çalışmada ergenlik döneminde ebeveyn tutumları ve duygusal zekâ arasındaki direk ve dolaylı etkiler incelenmiş ve benlik sayg1sının aracı etkisi araştırılmıştır. Araştırmanın amacı doğrultusunda öncelikle araştırmanın değişkenleri arasındaki ilişkiler ortaya konmuş daha sonra demokratik, otoriter ve koruyucu-istekçi ebeveyn tutumları ile duygusal zekâ arasında benlik saygısının aracı etkisi araştırılmıştır.

Demokratik ebeveyn tutumu için yapılan analizlerde öncelikle demokratik tutum ve benlik saygısı ile demokratik tutum ve duygusal zekânın olumlu ilişkili olduğu ve benlik saygısının ise bu ilişkiye kısmî olarak aracılık ettiği bulunmuştur. Otoriter tutum ise duygusal zekâ ile olumsuz yönde ilişkilidir ve bu ilişkiye benlik saygısı kısmî aracılık etmektedir. Diğer yandan koruyucuistekçi ebeveyn tutum değişkenin duygusal zekâ ile ilişkisi anlamlı bulunmadığından ayrıca koruyucu anne baba tutumunun benlik saygısına etkisi anlamsız bulunduğundan aracılık etkisine bakılması mümkün olmamıştır. Sonuçlar incelendiğinde demokratik ve otoriter ebeveyn tutumlarına dair analizlerin önceki araştırma sonuçları ile ve beklentilerle tutarlı olduğu görülmektedir.

Öncelikle demokratik ebeveyn tutumuna bakıldığında benlik saygısı ile olan olumlu ilişkisi bu konuda yapılmış olan geniş sayıdaki araştırma sonuçları ile tutarlık göstermektedir (Aktaş, 2011; Ceral ve Dağ, 2005; Mogonea ve Mogonea, 2014). Bu sonuçtan hareketle demokratik tutumun hem sevgi içermesi hem de bağımsızlığı desteklemesi sebebiyle benlik saygısının gelişiminde belirleyici olan ait olma ve keşfetme duygularını karşıladığı için söz konusu olumlu ilişki ortaya çıkmış olabilir (Brown, 1998; Demiriz ve Öğretir, 2007; Reitman ve ark., 2002). Benlik saygısının yanı sıra, demokratik tutumun duygusal zekâ ile olumlu ilişki göstermesi beklenen bir sonuçtur (Nastasa ve Sala, 2012). Abdollahi, Abu Talib ve Motalebi (2013) duygusal zekânın gelişiminde sevginin belirleyici bir faktör olduğunu belirtmişlerdir. Yine Alegre (2011), ebeveynin cevap verebilirliğinin, ebeveynin olumlu talepkârlığının çocuklarının duygusal zekâsını olumlu yönde belirlediğini belirtmiştir. Demokratik ebeveyn tutumu söz edilen özellikleri içerir görünmektedir. Benzer biçimde, Topuksal da (2011)'de demokratik anne baba tutumuna sahip öğrencilerin duygusal zekânın kişilerarası ilişkiler, stres yönetimi ve uyum boyutlarında yüksek puan aldıklarını ortaya koymuştur.

Otoriter tutum için yapılan analizlerde de otoriter tutum ve duygusal zekâ ve benlik saygısı arasındaki olumsuz ilişki ve benlik saygısı ve duygusal 
zekâ arasındaki olumlu ilişki görülmektedir. Giriş bölümünde aktarıldığı gibi, otoriter tutum hem baskıyı içerdiği hem de özerklik girişimini engellediği için hem benlik saygısı kazanımında belirleyici olan ait olma ve keşif duygularını, hem de duygusal zekâ gelişimi için önemli kabul edilen ebeveyn sıcaklığı, şefkati gibi duyguların ifadesini içermediği için sonuçlar beklendik ve alanyazınla tutarlıdır (Nastasa ve Sala, 2012; Özgüven, 2001; Şendil, 2003).

Benlik saygısının aracı etkisi incelendiğinde değişkenin hem demokratik tutum için yapılan analizlerde hem de otoriter tutum için yapılan analizlerde ebeveyn tutumları ve duygusal zekâ arasındaki ilişkiye kısmî aracılık ettiği bulunmuştur. Yani, araştırmamızın örneklemi için sonuçlar, ergenlik döneminde algılanan ebeveyn tutumu önemini korumakla beraber benlik sayg1sının da duygusal zekâ üzerinde belirleyici olduğunu ortaya koymaktadır. Bu sonuç, öncelikle, ebeveyn tutumlarının ergenlik dönemindeki önemini gösteren çalışmalarla tutarlıdır. Örneğin, Laible, Carlo ve Roesch'nın (2004) da ebeveyne ve akranlara bağlanmanın ergenlerde benlik saygısı üzerinde en fazla etkisi olan değişken olduğunu ortaya koymaktadır. Diğer yandan ergenlik dönemi çocukluktan farklı olarak ebeveyn tutumlarının yansıra birçok faktörün de duygusal zekâ konusunda belirleyici olabildiği bir dönemdir. Bilindiği gibi bu dönem, fiziksel, bilişsel, toplumsal ve duygusal değişimlerin yaşandığ bir dönemdir ve bütün bunlar karmaşık duyguların yoğun olarak yaşanmasına yol açabilir. Bu nedenle söz konusu gelişimsel dönemin gerekliliği ile başa çıkabilmek için ergenin kendi duygularını anlaması, diğerinin duygularını anlayabilmesi ve dış dünyanın zorluk ve talepleri ile başa çıkma becerisi geliştirmesi önemlidir. Söz edilen duygusal zekânın bileşenleri olan bu beceriler konusunda benlik saygısının yüksekliği önemli bir belirleyici olabilir (Bar-On, 2006). Yüksek benlik saygısı olumlu duygu durumu ile ilişkili, kaygı gibi olumsuz duygular için tampon görevi gören, özellikle başarısızlık karş1sında duygusal düzenleme açısından avantaj sağlayan bir kavramdır. Ayrıca benlik saygısı yüksek olan bireylerin duyguyu bilgi sağlayıcı olarak kullanabilme becerileri de onlara hayatın birçok alanına adapte olabilmek konusunda avantaj sağlamaktadır (Harber, 2005; Leary, Tambor, Terdal ve Downs, 1995; Smith ve Petty, 1995). Bu bağlamda benlik saygısının yüksekliğinin, yüksek duygusal zekâ ile ilişkili olması ve ebeveyn tutumları ile olan ilişkisinde kısmî aracı olması araştırmanın beklentileri ve önceki sonuçlar ile tutarlıdır. Sözü edilen bu kısmî aracılık etkisine dayanarak duygusal zekânın gelişimi konusunda pratik önerilerde bulunmak mümkündür. Araştırma sonuçları ergenlerde duygusal zekânın önemli bir belirleyicisinin ebeveyn tutumları 
olduğunu, özellikle demokratik ebeveyn tutumunun önemini ortaya koymaktadır. Bu noktada duygusal zekâyı geliştirmek için bir yol olarak olumsuz ebeveyn tutumlarını değiştirmeye çalışmak düşünülebilir. Ancak, yetişkin insanların tutumlarını değiştirmek kolayca gerçekleşecek bir durum değildir. Diğer yandan ergenlik döneminde benlik saygısının, ebeveyn tutumları dışındaki akranlar, akademik ve sportif faaliyet, karşı cins tarafindan kabul edilmek, öğretmenlerle ilişkiler gibi çok farklı kaynaklardan beslendiği düşünülürse duygusal zekâyı geliştirmek için ergenlerde benlik saygısını çeşitli yollarla desteklemek ve yükseltmek mümkün olabilir. Kısacası bu sonuç pratik olarak da yararl1 olabilir.

Sonuç olarak buraya kadar araştırmanın direk ve aracı etkiye dair beklentileri önemli ölçüde doğrulanmıştır ve alanyazınla tutarlık göstermektedir. Diğer yandan koruyucu istekçi tutuma ait doğrudan ve dolaylı etkilerin doğrulanmamış oluşu araştırmacıların beklentisi dışındadır. Daha önce aktarıldığı gibi bu tutum çocuğun özerkleşmesine izin vermeyen, onun yerine sorumluluk almayı içeren ve aşırı derecede koruyucu davranışları içeren bir tutumdur (Kulaksızoğlu, 2011; Yörükoğlu, 1990). Böyle bir tutum demokratik tutumda ait olmayı ve keşfetmeyi ve otoriter tutumda var olan duygusal açıdan ketlenmeyi içermediği, kısacası ne sevgiyi ve ne de olumsuz duygusalları içermediği için duyguya yönelik değişkenlerle ilişkisiz olabilir. Ülkemizde yapılan bir başka çalışmada ergenlerde benlik algısı ve ebeveyn tutumları arasındaki ilişki incelenmiş ve çalışmamızla benzer bir biçimde demokratik ve otoriter ebeveyn tutumuna ilişkin anlamlı sonuçlar bulunmuş olmasına karşın, koruyucu-istekçi ebeveyn tutum puanları açısından kendilik algıları düşük, orta ve yüksek grupta olan katılımcılar farklılaşmamıştır. Yine de ülkemizde koruyucu-istekçi ebeveyn tutumu ve duygusal gelişim ilişkisini inceleyen daha fazla ça1ışma yapılması konunun derinlemesine anlaşılması konusunda yararlı olabilir (Sezer, 2010).

Çalışma aynı zamanda bazı sınırlılıklara sahiptir. Öncelikle araştırmanın örneklem sayısının sınırlı olması araştırmanın genellenememesine neden olmaktadır. Çalışmanın örneklemini 10-15 yaş arası katılımcılar oluşturmaktadır. Bu geniş ranj çalışmadan elde edilen bulguların genellenmesinde problem oluşturabilir. Ayrıca, bu araştırmanın verileri İstanbul ili Kadıköy ilçesine bağlı özel bir ortaokulda öğrenim gören sosyo-ekonomik düzeyi orta veya yüksek ailelerden gelen ergenlerden elde edildiği için yapılacak genelleme de ancak benzer gruplar için geçerli olabilir. İleride farklı sosyo-ekonomik 
düzeylerden ve farklı illerden katılımcılarla yapılacak çalışmalar konunun derinlemesine anlaşılmasına yol açabilir. Ayrıca, bu çalışma benlik saygısının duygusal rolü vurgulamaktadır. İleriki çalışmalarda benlik saygısının yanı sıra olumlu olumsuz duygulanım, duygu düzenleme gibi diğer değişkenler de alınarak benlik saygısının farklı duygularla ve duygusal zekâ ile ilişkileri netleştirilebilir.

Sonuç olarak bu çalışma benlik saygısının hem demokratik hem de otoriter ebeveyn tutumu ile duygusal zekâ arasındaki kısmî aracılık etkisini göstererek ergenlerde benlik saygısının önemine dikkat çekmektedir.

\section{Kaynakça}

Abdollahi, S. A., Abutalib, M., Motalebi, S. A. (2013). Perceived parenting styles and emotional intelligence among Iranian boy students. Asian Journal of Social Sciences \& Humanities, 2(3), 460-467.

Aktaş, S. (2011). 9. sınıfta anne baba tutumları ve benlik saygısı arasındaki ilişkinin bazı değişkenler açısından incelenmesi. Yayınlanmamış doktora tezi, Selçuk Üniversitesi Eğitim Bilimleri Enstitüsü.

Alegre, A. (2011). Parenting styles and children's emotional intelligence: What do we know? The Family Journal, 19(1), 56-62.

Balat, G. U., Akman, B. (2004). Farklı sosyo-ekonomik düzeydeki lise öğrencilerinin benlik saygısı düzeylerinin incelenmesi. Frrat Üniversitesi Sosyal Bilimler Dergisi, 14(2), 175-183.

Bar-On, R. (2006). The Bar-on model of emotional-social intelligence (ESI). Psicothema, 18, 13-25.

Baumeister, R. F., Campbell, J. D., Krueger, J. I. ve Vohs, K. D. (2003). Does high self-esteem cause better performance, interpersonal success, happiness, or healthier lifestyles? Psychological science in the public interest, 4(1), 1-44.

Brenner, V., ve Fox, R. A. (1999). An empirically derived classification of parenting practices. The Journal of Genetic Psychology, 160(3), 343356.

Brown, J. D. (1998). The self. Boston, Massachusetts: McGraw-Hill.

Brown, J. D. ve Marshall, M. A. (2001). Self-esteem and emotion: Some thoughts about feelings. Personality and Social Psychology 
Bulletin, 27(5), 575-584.

Campbell, J. D. (1990). Self-esteem and clarity of the self-concept. Journal of personality and social psychology, 59(3), 538-549.

Ceral, S. ve Dağ, İ. (2005). Ergenlerde algılanan anne baba tutumlarına bağlı benlik saygis1, depresiflik ve genel psikolojik belirti düzeyi farkl111kları. Psikiyatri Psikoloji Psikofarmakoloji (3P) Dergisi, 13(4), 233241.

Çukur, C. Ş., De Guzman, M. R. T. ve Carlo, G. (2004). Religiosity, values, and horizontal and vertical individualism-collectivism: A Study of Turkey, the United States, and the Philippines. The Journal of Social Psychology, 144(6), 613-634.

Darling, N. ve Steinberg, L. (1993). Parenting style as context: An integrative model. Psychological Bulletin, 113(3), 487-496.

Demiriz, S. ve Öğretir, D. (2007). Alt ve üst sosyo-ekonomik düzeydeki 10 yaş çocuklarının anne tutumlarının incelenmesi. Kastamonu Eğitim Dergisi, 15(1), 105-122.

Donnellan, M. B., Trzesniewski, K. H., Robins, R. W., Moffitt, T. E. ve Caspi, A. (2005). Low self-esteem is related to aggression, antisocial behavior, and delinquency. Psychological Science, 16(4), 328-335.

Driscoll, L. C. (2013). Parenting styles and self-esteem. Scripps Senior Theses. Paper 155.

http://scholarship.claremont.edu/scripps_theses/155

Greenberg, J., Solomon, S., Pyszczynski, T., Rosenblatt, A., Burling, J., Lyon, D., Simon, L. ve Pinel, E. (1992). Why do people need self-esteem? Converging evidence that self-esteem serves an anxiety-buffering function. Journal of Personality and Social Psychology, 63(6), 913-922.

Harber, K. D. (2005). Self-esteem and affect as information. Personality and Social Psychology Bulletin, 31(2), 276-288.

Hewitt, J. P. (2009). Self-esteem. S. J. Lopez, (Ed.), The encyclopedia of positive psychology Volume II, LZ içinde (880-881). United Kingdom: Wiley-Blackwell.

Karabulut, A. (2012). Baron ölçeği uyarlaması. Yayınlanmamış yüksek lisans tezi, Dokuz Eylül Üniversitesi Eğitim Bilimleri Enstitüsü. 
Karasar, N. (2010). Bilimsel araştırma yöntemi-kavramlar, ilkeler, teknikler (21. bask1). Ankara: Nobel Yayınevi.

Kulaksızoğlu, A. (2011). Ergenlik psikolojisi (13. baskı). İstanbul: Remzi Kitabevi.

Kuzgun, Y. ve Eldeleklioğlu, J. (2005). Ana baba tutumları ölçeği. PDR'de kullanılan ölçekler. Ankara: Nobel Yayın Dağıtım.

Laible, D. J., Carlo, G. ve Roesch, S. C. (2004). Pathways to self-esteem in late adolescence: The role of parent and peer attachment, empathy, and social behaviours. Journal of adolescence, 27(6), 703-716.

Lambird, K. H. ve Mann, T. (2006). When do ego threats lead to self-regulation failure? Negative consequences of defensive high self-esteem. Personality and social psychology bulletin, 32(9), 1177-1187.

Leary, M. R., Tambor, E. S., Terdal, S. K. ve Downs, D. L. (1995). Self-esteem as an interpersonal monitor: The sociometer hypothesis. Journal of Personality and Social Psychology, 68(3), 518-530.

Martínez, I., García, J. F. ve Yubero, S. (2007). Parenting styles and adolescents' self-esteem in Brazil. Psychological reports, 100(3), 731-745.

Mogonea, F. R. ve Mogonea, F. (2014). The role of the family in building adolescents' self-esteem. Procedia-Social and Behavioral Sciences, 127, 189-193.

Nastasa, L. E. ve Sala, K. (2012). Adolescents' emotional intelligence and parental styles. Procedia-Social and Behavioral Sciences, 33, 478-482.

Özgüven, İ. E. (2001). Ailede iletişim ve yaşam. Ankara: PDREM Yayınları.

Reitman, D., Rhode, P. C., Hupp, S. D. ve Altobello, C. (2002). Development and validation of the parental authority questionnaire-revised. Journal of Psychopathology and Behavioral Assessment, 24(2), 119-127.

Rey, L., Extremera, N. ve Pena, M. (2011). Perceived emotional intelligence, self-esteem and life satisfaction in adolescents. Psychosocial Intervention, 20(2).

Salovey, P. ve Mayer, J. D. (1990). Emotional intelligence. Imagination, cognition and personality, 9(3), 185-211.

Schutte, N. S., Malouff, J. M., Simunek, M., McKenley, J. ve Hollander, S. 
(2002). Characteristic emotional intelligence and emotional well-being. Cognition \& Emotion, 16(6), 769-785.

Sezer, Ö. (2010). Ergenlerin kendilik algılarının anne baba tutumları ve bazı faktörlerle ilişkisi. Yüzüncü Yll Üniversitesi Eğitim Fakültesi Dergisi, 7(1), 1-19.

Smith, S. M. ve Petty, R. E. (1995). Personality moderators of mood congruency effects on cognition: The role of self-esteem and negative mood regulation. Journal of personality and social psychology, 68(6), 10921107.

Şendil, G. (2003). Çocuk, ergen ve anne baba. İstanbul: Çantay Yayınları.

Topuksal, D. (2011). İlköğretim ikinci kademe öğrencilerinin duygusal zeka düzeylerinin ana baba tutumları açısından incelenmesi. Yayınlanmamış yüksek lisans tezi, Çukurova Üniversitesi Sosyal Bilimler Enstitüsü.

Trzesniewski, K. H., Donnellan, M. B., Moffitt, T. E., Robins, R. W., Poulton, R. ve Caspi, A. (2006). Low self-esteem during adolescence predicts poor health, criminal behavior, and limited economic prospects during adulthood. Developmental psychology, 42(2), 381-390.

Usborne, E. ve Taylor, D. M. (2010). The role of cultural identity clarity for self-concept clarity, self-esteem, and subjective well-being. Personality and Social Psychology Bulletin, 36(7), 883-897.

Verkuyten, M. ve Hagendoorn, L. (2002). In-group favoritism and self-esteem: The role of identity level and trait valence. Group Processes \& Intergroup Relations, 5(4), 285-297.

Yörükoğlu, A. (1990). Gençlik çă̆ı ruh să̆ğğ ve ruhsal sorunlar. İstanbul: Özgür Yayıncılık. 